J. Asiat. Soc. Bangladesh, Sci. 46(2): 163-178, December 2020

\title{
ACCESSIBILITY ANALYSIS OF CYCLONE SHELTERS - A CASE STUDY FOR ATULIA UNION, SATKHIRA, BANGLADESH
}

\author{
TANZIM HAYAT $^{1}$, A.S.M. MAKSUD KAMAL ${ }^{1}$, MD. SHAKHAWAT HOSSAIN ${ }^{1 *}$, \\ SAIYEBA ZAMAN ${ }^{1}$, B.M. RABBY HOSSAIN ${ }^{1}$ AND TAPAS RANJAN \\ CHAKRABORTY ${ }^{2}$ \\ ${ }^{I}$ Department of Disaster Science and Management, University of Dhaka, \\ Dhaka-1000, Bangladesh \\ ${ }^{2}$ Disaster Risk Financing Coordinator, Oxfam
}

\begin{abstract}
Cyclone shelters are considered as a solution to reduce cyclone risk in coastal districts of Bangladesh. The location of a shelter plays a crucial part in a potential user's decisionmaking process. If the perception is that the shelter is too far away, the user may decide not to use it. On the other hand, it would not be financially feasible to construct shelters near every settlement cluster. Therefore, network analysis using GIS has been applied to reveal the optimal location. Apart from distance, there are some other factors (like space, presence of gender segregated rooms and toilets, ramped access way, availability of drinking water, etc.), which affect a user's affinity to evacuate to a specific shelter. All the shelters in Atulia Union from Satkhira District of Bangladesh were visited to identify these characteristics. Finally, an index was developed to determine the preference of each shelter to its potential users. It was found that there is inadequate number of shelters in the study area and two new shelter locations were recommended.
\end{abstract}

Key words: Cyclone, Shelter, Accessibility, Optimal Location

\section{Introduction}

The Bay of Bengal is a hotspot for forming tropical low-pressure systems (i.e., the first stage of cyclone formation) (Paul 2009). About 10 percent of all the tropical cyclones in the world form here (Ali 1996). On average, a severe cyclone strikes Bangladesh every 3 years (Government of Bangladesh 2009). The country has experienced over 70 severe cyclones (associated with storm surges) from 1797 to 2007 (Khan 1995). In 1970, Cyclone Bhola, the deadliest recorded cyclone in human history, took about 300,000 lives and caused widespread damage to its infrastructure and economy (Hossain et al. 2008). However, recent studies suggest that the number of deaths resulting from storm surge has decreased like; Cyclone Sidr (2007) claimed the lives of 3,363 people despite being of the same category as cyclone Bhola (1970) due to improved state of preparedness and better infrastructure (Jia 2010).

*Corresponding author: <shakhawat.dsm@du.ac.bd>. 
Consequently, the combination of multiple factors is responsible for the frequent occurrence of cyclones and their immense damages. The damages are primarily due to the associated surges rather than the cyclones themselves. Firstly, it is the country's location, being just beside the Bay of Bengal and its funnel shaped coastline. Secondly, it is a low-lying delta incised by a multitude of rivers. The third factor is the volume of the population residing along the coasts of Bangladesh (that amounts to about 48 million or around 30 percent of the total population) and their general socio-economic status and prevalence of poverty. Fourthly, it is the presence (or rather the absence) of quality infrastructures like roads, polders, shelters and various other structures (Paul 2009, Jia 2010, BBS 2011).

Moreover, climate change is likely to exacerbate the frequency and severity of cyclones. Intergovernmental Panel on Climate Change (IPCC) suggests that the rise of sea surface temperature between 2 to $4^{\circ} \mathrm{C}$ can correlate with an increase in tropical cyclone frequency (IPCC 2014). Furthermore, any rise in Sea Surface Temperature could "fuel" the weaker depressions/cyclones, increasing their intensities and consequences (Ali 1996, Huq et al. 2010, IPCC 2014).

As was stated previously, there is overwhelming evidence suggesting cyclones are a frequent occurrence in coastal parts of Bangladesh. These cyclones are quite devastating as well. Approximately 53 percent of the cyclones with 5,000 or more casualties have occurred in Bangladesh and 49 percent of the world's cyclone related casualties were incurred in Bangladesh (Ali 1999, Government of Bangladesh 2008, Paul and Routray 2013). Therefore, it is not surprising that the 2011 Global Assessment Report of the UNISDR ranks Bangladesh sixth out of 89 countries regarding the number of people exposed to a cyclone (United Nations International Strategy for Disaster Reduction 2011).

World Bank (2010) shows that a significant portion of the population in Shyamnagar (an Upazila of Satkhira, located in the southwestern part of Bangladesh) transitions around the poverty line. Since Atulia Union is situated in Shyamnagar, it is true for its residents as well. The lack of sustainable income sources throughout the year substantiates their vulnerability (Fenton et al. 2017). This translates as large portion of the people being unable to afford resilient housing and end up living in Kacha or Semi-Pucca houses (Islam et al. 2015). These houses are not strong enough to resist the winds and surges associated with cyclones, thus exposing them to greater risks. This was one of the foremost reasons behind the high number of lives lost in the 1970 and 1991 Cyclones. Although resilient housing for everyone would dramatically reduce risks, it was not 
financially possible. Therefore, the government decided to build cyclone shelters (CS) to reduce the consequences of cyclone disaster. Despite the success of such a measure, there are other factors that motivate people actually to use shelters like cyclone forecasting ability, the ability to generate trustworthy, accurate warning signals, dissemination of such information to the vulnerable communities, distance and 'access' to cyclone shelters (Paul 2009). Paul and Routray (2013), along with Roy et al. (2015) showed that coastal inhabitants are aware of the risks resulting from cyclones but "choose" not to respond because of poor road networks, long distances between home and shelters, low capacity of shelters to accommodate everyone and fear of household goods being stolen.

The objective of this paper is to investigate the current location of the shelters in Atulia Union and how accessible they are, given the crucial role they play in the disaster preparedness phase. Since the accessibility of shelters depends not only on distance but also on the available facilities, the paper will provide an overview of the facilities within each individual cyclone shelter.

\section{Materials and Methods}

Study area: The study was conducted in the Atulia Union (one of the smallest administrative divisions of Bangladesh) of Shyamnagar Upazila of Satkhira District, situated in the southeastern corner of Bangladesh (Fig. 1) in the month of February, 2018. The total population of the Atulia Union is about 42,000, with area of 4,475,823.2 square meter. Around $25 \%$ of families survive below the poverty line (Atulia Union Parishad 2018). Atulia is situated beside the Kholpetua River, which flows out to the Bay of Bengal. Storm surges travel through the river unimpeded and the relative height of the surges is greater due to its proximity from the Bay. This provides motivation to determine the distance to be traversed by people to their nearest shelter since they are amongst the first population who experience the surge and every minute is crucial. In addition, the study determines whether the facilities within the shelters are suitable. Moreover, the level of poverty in the study area also means that there are many people who need to use the shelters, thus it is essential to figure out whether they may be able to access the shelters when the time comes. The study is even more relevant since, in previous times, many lives were lost due to inadequate preparedness. In 1991 and 2009, the Cyclones Gorky and Aila had caused widespread damages and casualties to this region (IFRC 2002, 2009). 


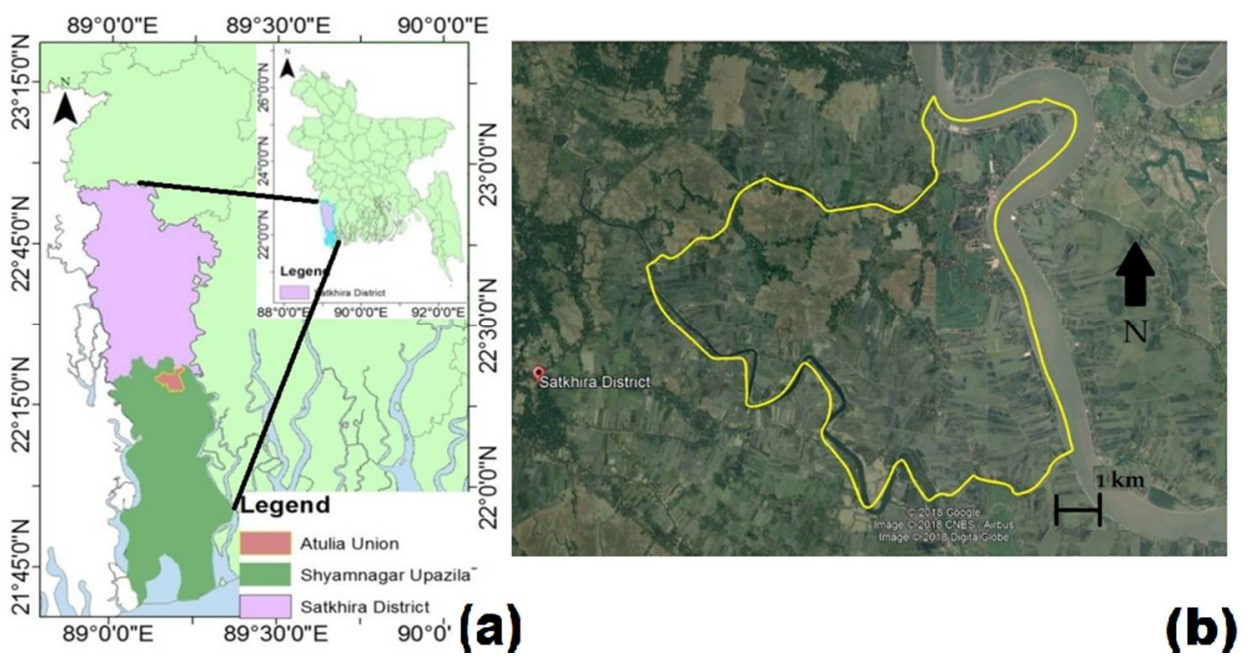

Fig. 1 (a) Location of the Atulia Union in reference to Satkhira (Local Government Engineering Department 2018), (b) The Satellite image by Google Earth (2021) of the Atulia union is shown with a yellow border.

Methodology: Initially, literature review and expert opinions helped to illustrate the overall situation as well as to identify the potential gap and research objectives, i.e., to carry out accessibility analysis, which would become a useful resource for future infrastructure development and maintenance. The experts included an NGO professional, a University Professor and researchers who worked on cyclone disaster risk. In addition, a field reconnaissance survey, Focus Group Discussions (FGD) and Key Informant Interviews (KII) were conducted to collect primary data, like locations of shelter, settlements, roads, different shelter facilities and walking speeds. These were combined with secondary data that included population, satellite images (to digitize road networks) and settlement clusters. Finally, the travel times to each shelter was computed using Network Analysis. Afterward, an index was created to condense the travel time data with individual shelter facilities to understand the current accessibility of each shelter. The term accessibility used here means the ease of a potential user of the shelter to use it. Finally, two new optimal shelter locations were suggested. The methodological framework adopted for this study is given in Fig. 2.

Initially, three FGDs were conducted to identify the overall distribution and location of existing CS in the study area, along with road conditions and the hindrances people face when accessing them. Most FGDs had around 10 members (Focus Group Discussion 2020). The later FGDs and 20 KIIs were with people who have already used the shelters 
in crisis times or were potential users. While FGDs revealed broad problems, like lack of nearby shelters, or low quality of access roads, KIIs helped to shed light on details of the facilities within the shelters. For instance, a shelter may have good access roads, but a portion of it becomes very slippery during the monsoon. The data obtained from KII helped to determine how long it takes for people to walk a certain distance on a normal day compared to if they use a van. The walking time for elders and pregnant women were also determined. Furthermore, it helped to find the shelter capacity and various factors included in Table 1, 2 and 3. This formed the core data in the research. In addition, KIIs were conducted with the Chairman (Union Parishad), Disaster Management Committee members, members of the Cyclone Shelter Management Committee (including teachers/Principals of the School/College which are used as CS and various users of the shelters (including disadvantaged people like the elderly and women). The purpose was to identify the qualities of specific shelters that affected their affinity to evacuate to that shelter.

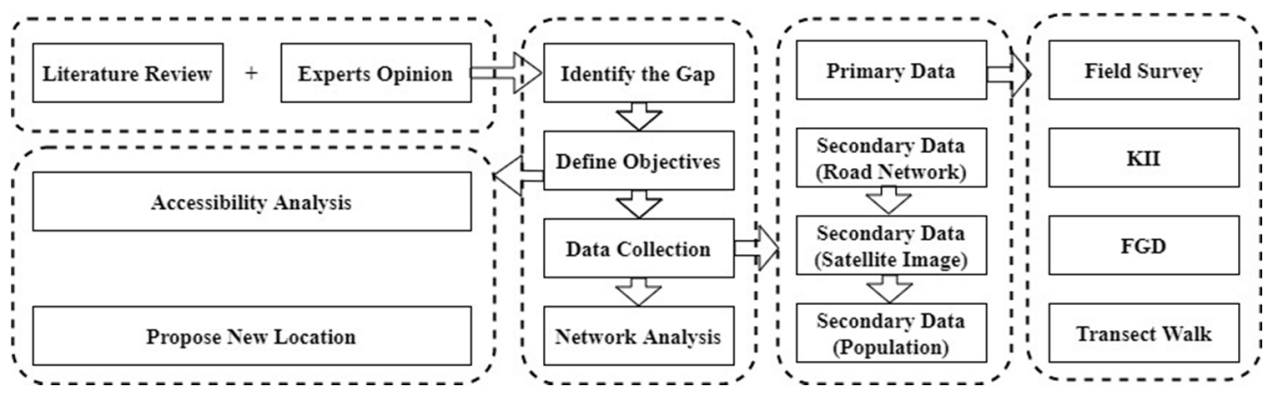

Fig. 2. Methodological Framework.

Only public buildings with more than or equal to two story were considered as shelters, because the surge heights can reach about 3 to 5 meters in height, which would easily drown single story buildings. Furthermore, an individual inspection of each cyclone shelter was conducted, and their near-exact Geolocations was recorded with a Calibrated Garmin GPS and Android device. During those inspections, a checklist was used to record the conditions of the structure and various facilities of the shelter (Table 2). Moreover, the checklists contained fields for location information; access road's condition; the number of floors, rooms and floor size; actual and recommended capacity; the presence of ramps; domestic animal storage space; the number of toilets and their height above ground; water source and storage; the presence of solar based fan, lights; and presence of visible structural defects. Such information was then cross matched 
during the KIIs with the users. The conditions and types of roads were also recorded from field observation.

The recorded locations of the shelters, settlements, and roads were translated into shapefiles. Digitized roads and settlement cluster locations were re-examined in Google Earth to ensure that their identification, condition and extent were accurate. Whereas, the number of inhabitants of the settlements was interpolated based on the area (i.e. size) and density of each cluster. To find the shortest distance from settlement to shelters and to identify the closest shelter for each settlement cluster, the ArcGIS Network Analyst tool was utilized (ArcGIS Network Analyst Overview 2020).

\section{Results and Discussions}

Both KIIs and FGDs revealed that the population who were currently living in two-story concrete housings were using their houses as shelters rather than going to the CS. It is obvious that those who live in substandard housing require better shelters during an emergency. However, the population will willingly choose not to go to one when the need arises. Their reason for choosing such action varies, as has been studied by Roy et al. (2015). One of the demotivating factors is the distance to the shelters. The distance data is calculated using the Closest Facility tool. This is placed under 'Road Length max.' (Table 1). The term means a shelter's distance from the farthest settlement, from which people will actually travel to the shelter. The second column of the Table 1 (Walk time normal) shows the time taken to walk (the maximum road length) for a normal person on a normal day. The third column represents the walking time of the most vulnerable groups (such as elders, pregnant women, children, etc.) on rainy days. The fourth column represents the time it would take to travel on a van. Access roads denote the type of road (Kacha- bare soil, Pucca- asphalt).

In the study area, nine shelters are located more than $1500 \mathrm{~m}$ away from settlements, which is deviatory from the recommendations of Cyclone Shelter Construction, Maintenance and Management Policy 2011. Shelters are usually placed near the largest settlement catchments (owing to the multipurpose use of the structures as educationalinstitutions). This, on the other hand, shows that remote settlement catchments do not have shelters nearer to them. In terms of distance, it may seem that accessing CS 2 and 6 are similar, but further review reveals that their access roads have different conditions. For CS 2 the entire connecting road is bricked or even Kacha. This means that it takes longer to travel compared to CS 6 Pucca roads. This is reflected in the second column (Table 1- 'Walk time normal' column), which is not simply a function of their average 
walking speeds; rather, the value is based on the experience of the local people. The road length is the result of network analysis and the different times were based on information obtained from locals during KIIs and FGDs. When the factor of rain is included (in the third column), roads which are Kacha or Bricked (Fig. 3) pose a greater risk for the evacuees, especially risky for pregnant women, thus needs more time to travel. Pink lines in Fig. 3 indicate Pucca roads (good quality roads that are concrete or ashphalt). Orange Lines show roads that either has craters or are not constructed with Pucca road materials, making them less friendly to pedestrians or traffic. Both secondary data (Local Government Engineering Department 2018) and primary observations have been used to generate this map. This accounts for the conditions that the people might face during an actual evacuation, when heavy torrential rains are common during cyclones. The fourth column represents the time it would take to travel on a van. Given that, people only start to evacuate in the "eleventh hour" the travel time forms an important element in determining the accessibility of the shelters.

Table 1. Maximum length (metres) of roads and the time (minutes) taken to traverse them.

\begin{tabular}{lccccl}
\hline Shelter name & $\begin{array}{c}\text { Road length } \\
(\text { max. })(\mathrm{m})\end{array}$ & $\begin{array}{c}\text { Walk time } \\
\text { normal (min) }\end{array}$ & $\begin{array}{c}\text { Walk time } \\
\text { slowest } \\
(\mathrm{min})\end{array}$ & $\begin{array}{c}\text { Van } \\
\text { time } \\
(\mathrm{min})\end{array}$ & $\begin{array}{l}\text { Access } \\
\text { road }\end{array}$ \\
\hline 1- Atulia CS1 & 1582 & 25 & 56 & 16 & Pucca \\
2-Boro Kupot Primary (81) & 2409 & 40 & 96 & 25 & Bricked \\
3-Kashimari Primary & 880 & 22 & 53 & 8 & Pucca \\
4-Rabeya Dakhil Madrasa & 617 & 13 & 30 & 3 & Pucca \\
5-Beralakkhi Madrasa & 1331 & 22 & 53 & 15 & Bricked \\
6-Noabeki Mahabiddyaloy & 2417 & 34 & 59 & 7 & Pucca \\
7-Beralakkhi Primary (146) & 1474 & 24 & 58 & 17 & Bricked \\
8-Kachari Bridge School & 2235 & 25 & 60 & 12 & Pucca \\
9-Abdul Kader High School & 2657 & 34 & 82 & 20 & Pucca \\
10-Atulia Primary (40) & 2707 & 45 & 108 & 28 & Kacha \\
11-Choto Kupot Primary(41) & 2073 & 40 & 96 & 25 & Kacha \\
12-Choto Kupot Primary(89) & 1979 & 40 & 97 & 20 & Bricked \\
13-Henchi High School & 2913 & 57 & 137 & 32 & Bricked \\
\hline
\end{tabular}

Source: Field survey, 2018.

Apart from the distance and difficulty of evacuation, there needs to be a consideration of the facilities within the shelter itself. A compilation of such facilities has been made from observation in Table 2. Significant among those, is access to water and a sanitation system that remains functional during the emergency. Access to fresh drinking water was 
seen to be ensured by installations of large capacity tanks (>5,000 litres) for all the shelters except for CS 9. The tube well was not raised but was at ground level, which meant it would be drowned by surges. The presence of solar lights ensures that even when the main electricity is disrupted, there is a source of light in the shelter.

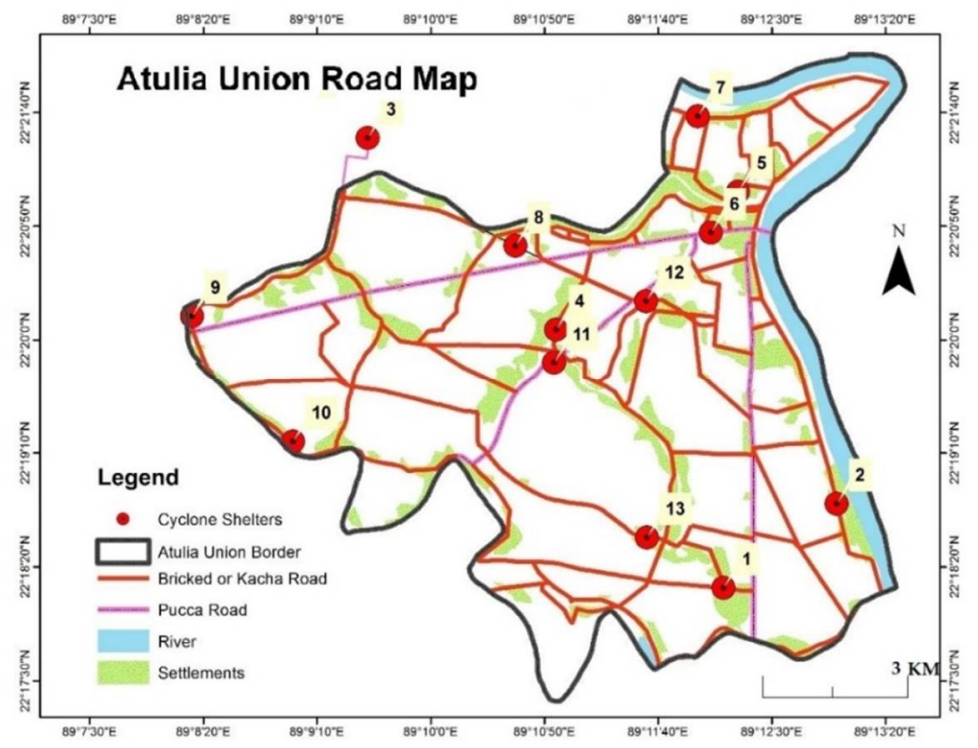

Source: Field survey, 2018.

Fig. 3. Road map of Atulia, with the classification of its types.

Even though all the structures (Table 2) have two stories or more, many of the older school buildings (like CS $11 \& 12$ ) only had toilets on the ground floor, which would be rendered unusable after surges. Fresh water source is an important factor for evacuees, so the presence of water tanks to store groundwater (GW) or from rain harvesting (RWH) was seen in all but 1 cyclone shelter. Ramp entry helps those who cannot climb stairs to reach higher stories in the shelter. Also, if toilets are not raised, but are at ground level, then during surge induced flooding, they cannot be used. According to locals, the surving water can take two days or more to recede, so the availability of a toilet is crucial in determining the shelter's usability. On a positive note, all the toilets were gendersegregated, conducive to the local customs.

The holding capacity is determined by the size of the building and the number of floors. The data has been collected from observation and KIIs. The settlement field indicates the total population each shelter is meant to serve. The difference shows the population of people who cannot take shelter in the designated building. CS 6 and CS2 have the highest 
difference meaning their size and capacity differ a lot. In contrast, CS 4 has the lowest difference, which means that their sizes are more appropriate according to the size of the population they are meant to serve.

None of the shelters had ramped access ways or cattle storage space except three (CS 6, 7 and 10). This means people have to climb stairs, which can prove to be difficult for the elderly and pregnant women. Most of the shelters had solar panels for lighting. All the shelters were originally supplied with panels, but some were no longer functional and are yet to be replaced. Solar powered lights are considered a useful utility as the presence of lights at night can provide a sense of security.

Major structural damages were noticed in CS 2 (Figure 4) and 10, where load-bearing columns had fractures and concrete spalling. These demand immediate repair before they can be used as shelters. In fact, these shelters have not been repaired since they incurred damage in Cyclone Aila. The saline surge water exposure has possibly increased the process of concrete deterioration, according to the opinion of locals.

Table 2. Summary of shelter conditions.

\begin{tabular}{|c|c|c|c|c|c|}
\hline Shelter name & $\begin{array}{l}\text { Water } \\
\text { source }\end{array}$ & $\begin{array}{l}\text { Solar } \\
\text { lights }\end{array}$ & $\begin{array}{l}\text { Ramp } \\
\text { entry way }\end{array}$ & $\begin{array}{l}\text { No. of } \\
\text { toilets }\end{array}$ & $\begin{array}{l}\text { Structural } \\
\text { damage }\end{array}$ \\
\hline 1- Atulia CS1 & Tank(GW) & Yes & No & 2 (Ground) & Not found \\
\hline 2-Boro Kupot Primary (81) & Tank(RWH) & No & No & 2 (Ground) & Major \\
\hline 3-Kashimari Primary & Tank(RWH) & Yes & No & 2 (Ground) & Not found \\
\hline 4-Rabeya Dakhil Madrasa & $\operatorname{Tank}(\mathrm{GW})$ & Yes & No & 6 (Raised) & Not found \\
\hline 5-Beralakkhi Madrasa & $\operatorname{Tank}(\mathrm{GW})$ & No & No & 6 (Raised) & Negligible \\
\hline 6-Noabeki Mahabiddyaloy & $\operatorname{Tank}(\mathrm{RWH})$ & Yes & Yes & 4 (Raised) & Not found \\
\hline 7-Beralakkhi Primary (146) & Tank(RWH) & Yes & Yes & 4 (Raised) & Not found \\
\hline 8-Kachari Bridge School & Tank(RWH) & No & No & 2 (Ground) & Negligible \\
\hline 9-Abdul Kader High School & Tube well & Yes & No & 6 (Ground) & Not found \\
\hline 10-Atulia Primary (40) & Tank(RWH) & No & Yes & 2 (Ground) & Major \\
\hline 11-Choto Kupot Primary(41) & Tank(RWH) & Yes & No & 2 (Ground) & Not found \\
\hline 12-Choto Kupot Primary(89) & $\operatorname{Tank}(\mathrm{RWH})$ & No & No & 2 (Ground) & Not found \\
\hline 13-Henchi High School & Tank(RWH) & Yes & No & 2 (Ground) & Negligible \\
\hline
\end{tabular}

Source: Field survey, 2018.

Apart from these shelters, there are about 350 double story structures in the union. The figure is an estimate obtained from locals during FGDs and KIIs. Most of those structures are being used as residents. These serve as impromptu/transitional shelters. People have reported that the owners of such structures allow others to take shelter without much 
discrimination. However, having relatives accelerates the process and may offer the advantage of having space "reserved" for them. People, who are not familiar with the owners of such structures, may have to visit many buildings before they find space. This is because often times the closest structures are "reserved" or already occupied by people familiar with their owners. This factor also serves as a crucial stepping-stone in the decision-making process of potential evacuees. Some fear the rejection and decide not to evacuate at all.



Fig. 4. The extent of structural damage of CS 2 Boro Kupot Primary (81) can be seen to be extreme. The column, which had the load bearing responsibility, has become fragile with the concrete spalling. Moreover, the rods are exposed to air and is rusting away, substantially decreasing their strength.

These structures can accommodate up to 60 people on average. Simple arithmetic shows that about 21,000 evacuees (in addition to the owners) can take refuge there. However, the location of these structures is not uniformly distributed. In addition, people have predominantly reported (contrary to the norms reported in the 1991 Gorky Cyclone evacuation) that they send the most vulnerable members (elders, women, children, etc.) first, with the male household head evacuating in the impending minutes. It is often seen that the population is threefold or more than the capacity of the shelters. It is this population who cannot access the shelters that travel to privately owned structures. 
Table 3. Summary of shelter capacity.

\begin{tabular}{lccc}
\hline Shelter Name & Capacity & Settlement & Difference \\
\hline 1- Atulia CS1 & 800 & 2600 & 1800 \\
2-Boro Kupot Primary (81) & 800 & 3800 & 3000 \\
3-Kashimari Primary & 700 & 2600 & 1900 \\
4-Rabeya Dakhil Madrasa & 1800 & 2700 & 900 \\
5-Beralakkhi Madrasa & 1500 & 3600 & 2100 \\
6-Noabeki Mahabiddyaloy & 1600 & 5400 & 3800 \\
7-Beralakkhi Primary (146) & 1600 & 3400 & 1800 \\
8-Kachari Bridge School & 1200 & 2400 & 1200 \\
9-Abdul Kader High School & 1600 & 2900 & 1300 \\
10-Atulia Primary (40) & 1000 & 3600 & 2600 \\
11-Choto Kupot Primary (41) & 800 & 2700 & 1900 \\
12-Choto Kupot Primary (89) & 800 & 2800 & 2000 \\
13-Henchi High School & 1000 & 3300 & 2300 \\
\hline
\end{tabular}

It is clear that accessibility depends on distance, road quality, and facilities within the CS. So to gain an overall idea of the accessibility of each shelter, an index has been developed (Table 4). The slowest walk time is the same indicator in the 3rd column of Table 1. It means the time taken to walk to the CS by older people on a rainy day. Population difference is the population greater than the shelter capacity. Water source indicates the presence of fresh drinking water in the shelters. To be considered unsustainable, there has to be an absence of storage tanks. The factor "Solar power" indicates the existence of working solar panels and lights. The presence of structural damage has been observed. The index translates the importance of each factor in the decision-making process of the evacuee using "Weights". The weights have been found by rank ordering technique during FGDs. The "Values" represent each factor's current condition. Like, if the distance to the shelter is too long, then the walk time increases. The greater the walk time, the higher is the value, which in turn indicates less accessibility. Similarly, the corresponding facilities of each shelter enable a value to be found, representing the accessibility of that shelter. This is compiled in Table 5. The higher the value, the less affinity it has to potential users.

As shown in Table 5, the greater the shelter score, the less attractive it is to its user. A score of $>25$ means it requires immediate attention, and that of around 15 means regular maintenance is due. This threshold value is based on local opinions. The score of CS 2 is the highest and therefore indicates to be the least desirable. The most impoverished road condition and major structural damages played a significant role in that score. Also, the longer distances in such roads also create difficulties for locals aiming to seek shelter 
elsewhere. This region had the least amount of privately owned double-story buildings, which meant the unaccommodated population had to travel long distances to find safety.

CS 10's relatively high score is contributed by its structural damages and low access road (Figure 5). The only access road leading to the shelter is simply a narrow pile of bare soil, reported being notoriously slippery during rains. Figure 5 shows the route of each settlement cluster to their corresponding cyclone shelter.

In Fig. 5, it can be seen that there are multiple roads leading to each shelter. For instance, about 9 roads connected to CS13. The length of these roads is not the same. The roads coming from the west are much longer than the roads on the east. The longest road has been considered when calculating the accessibility. This is because the accessibility of the people who live the farthest away from the shelter is prioritized to represent the worst-case scenario.

Table 4. The Table describes the weighting criteria for index scoring.

\begin{tabular}{cllll}
\hline Weight & Factor & & \multicolumn{2}{c}{ Values } \\
\hline 2 & Slowest walk time & 1 if $<60$ minutes & 2 if $>60$ minutes & \\
4 & Population difference & 1 if $<2000$ & 2 if $<2500$ & 3 if $>2500$ \\
1 & Water Source & 0 if Sustainable & 1 otherwise & \\
1 & Toilets & 0 if Present & 1 otherwise & \\
1 & Solar Power & 0 if Sustainable & 1 otherwise & \\
5 & Structural Damage & 0 if Absent & 1 if present & \\
6 & Road Condition & 0 if Pucca & 1 if moderate & 2 if severely damaged \\
\hline
\end{tabular}

Table 5. Accessibility Score of each shelter.

\begin{tabular}{lclc}
\hline Name & Index score & Name & Index score \\
\hline 1- Atulia CS1 & 7 & 8-Kachari Bridge School & 10 \\
2-Boro Kupot Primary (81) & 35 & 9-Abdul Kader High School & 10 \\
3-Kashimari Primary & 7 & 10-Atulia Primary (40) & 31 \\
4-Rabeya Dakhil Madrasa & 6 & 11-Choto Kupot Primary(41) & 15 \\
5-Beralakkhi Madrasa & 7 & 12-Choto Kupot Primary(89) & 16 \\
6-Noabeki Mahabiddyaloy & 6 & 13-Henchi High School & 13 \\
7-Beralakkhi Primary (146) & 12 & & \\
\hline
\end{tabular}

The index takes into account the holding capacity of people in the shelter, and, for CS 6, which has an unaccommodated population of 3,800 people, many of them actually live in their own double-story buildings and therefore do not go to the shelters. This is why its scores have gone down. Both CS 11 and 12 have roads with moderate damage, which is the reason behind their score. The rest of the shelters are in overall good condition but 
still require regular monitoring, especially before each cyclone season gives a better idea of why longer distances make shelters like CS 2 and CS 13 provide high scores even though they had adequate facilities within the shelters.

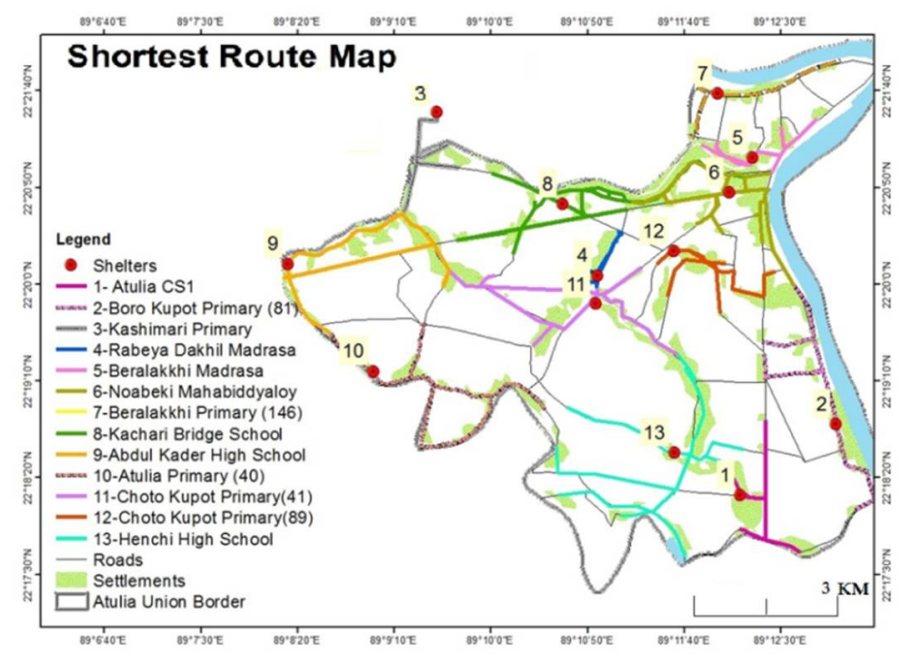

Fig. 5. Map of the shortest route.

The union has a current population of about 42,000, but shelters (both conventional and transitional) have a capacity of 38,000 (Table 3). Even if all the roads and shelters are fixed, 4,000 people still do not have any shelter. Therefore, it is logical to build newer shelters (Fig. 6) to benefit the maximum number of people in the union. Based on the shortest route calculation, the suggested location (14) will serve the greatest number of people by accommodating those in the CS 2 region who currently have the least desirable shelter, poor roads, and live far away from 2 story buildings. The capacity could be around 3,000. Given that, this community is directly beside the river, which brings in the surge, having a shelter nearby could be lifesaving. It will also benefit those, that have to travel the longest distances in the region of CS 12 and 13, by cutting their travel times by as much as half. The road conditions and shelter need to be fixed immediately for CS 10 to increase its desirability. As for the region south of CS 13 there existed no shelters at the time of the field visit. So, a suggestion could be to build a shelter of around 3,000 capacity (location 15). This will drastically reduce the pressure on CS 13. Many of the 2,100 unaccommodated people can then take shelter in Location 15 instead. If the access roads for CS 10 are not fixed, a portion of that population could travel to location 15 . 


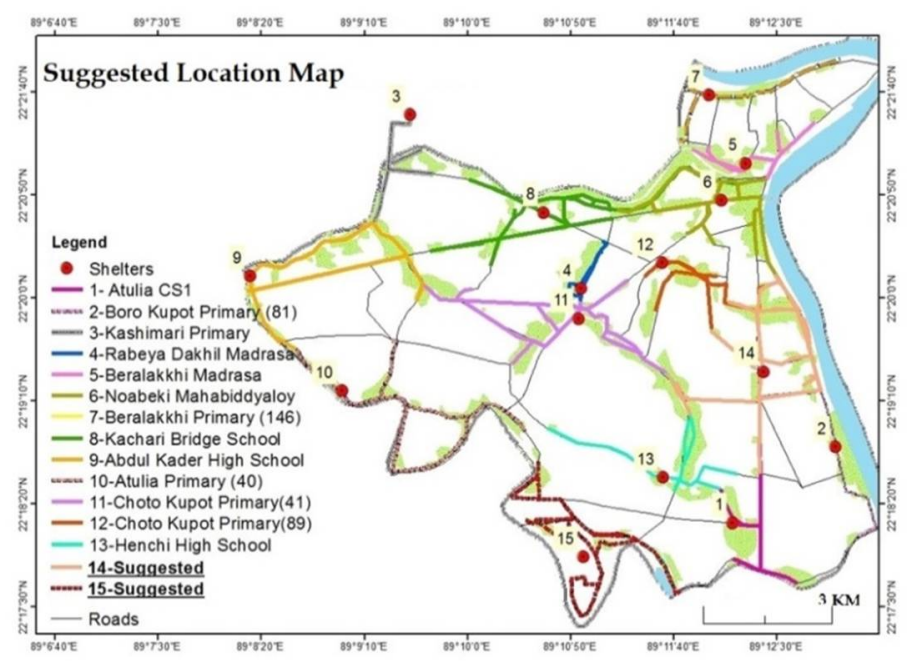

Fig. 6. Map showing suggested locations $(14 \& 15)$ for new construction.

There is no doubt that Bangladesh had significant progress in terms of Cyclone Preparedness. This is not only reflected in the infrastructure setting but also in the level of awareness of people. The manifold reduced casualties in Cyclone Aila compared to Cyclone Gorky stand testament to this fact. However, there are still credible risks, and not to mention gaps and challenges in Preparedness. When Atulia is taken as an example, it was seen that although 13 traditional shelters exist, they are by no measure enough. Even the capacity of those shelters quoted here is beyond the recommended thresholds $\left(3.75 \mathrm{~m}^{2}\right.$ per person) of the Government of Bangladesh Cyclone Shelter Management Policy. When infrastructure support proves inefficient, it is the social cohesion of the rural communities that enables them to survive. This cohesion alone is not sufficient. The research reveals that there are still about 4,000 people who would not have any shelter within the union.

The research suggests the two best possible sites to construct new shelters. The generated shortest route map can also be used for training or awareness raising purposes. It could serve as a guide for Cyclone Preparedness Programme Volunteers who would prefer to take the shortest routes during dissemination. The research also advocates the local administration to introduce awareness and training programs for resilient construction practices to ensure that shelters are safe and capable of withstanding surge impacts. In addition, older shelters are often not maintained, and they pose a risk of collapse or partial structural failure. 
In the context of rural Bangladesh, conventional Multipurpose Cyclone Shelters are still considered the best form of infrastructural support for Cyclone Preparedness (Amin et al. 2016). The research shows that through appropriate locational analysis, the selection of shelter construction plots could enhance preparedness. If that is done by following the

opinions of stakeholders (especially the locals), then a truly sustainable solution can be expected.

\section{Acknowledgments}

We thank Oxfam for funding the field visits. Shahidul Islam provided part of the Road network shapefile. Nafis Sazeed has provided support during field surveys. We also thank Ashraful Islam, Assistant Professor, Department of Geology, DU, for his guidance in structuring the paper.

\section{References}

Ali, A. 1996. Vulnerability of Bangladesh to climate change and sea level rise through tropical cyclones and storm surges. In: Water, Air, and Soil Pollution (Vol. 92, pp. 171-179). Kluwer Academic Publishers. https://doi.org/10.1007/978-94-017-1053-4_16

Ali, A. 1999. Climate change impacts and adaptation assessment in Bangladesh. Climate Research, 12:109-116. https://doi.org/10.3354/cr012109

Amin, M., S. Shil and M. Hasan. 2016. Status of cyclone shelter facilities in south central Bangladesh. Journal of Environmental Science and Natural Resources, 9(1), 75. https://doi.org/10.3329/jesnr.v9i1.30295

Atulia Union Parishad 2018. Budget Allocation Report', Ministry of Local Government, Rural Development and Co-operatives.

ArcGIS Network Analyst Overview 2020. Retrieved from https://www.esri.com/en-us/arcgis/ products/ArcGIS-network-analyst/overview (Accessed: 23 September 2020),

Bangladesh Bureau of Statistics 2011. Population \& Housing Census.

Fenton, A., J. Paavola and A. Tallontire 2017. The Role of Microfinance in Household Livelihood Adaptation in Satkhira District, Southwest Bangladesh, World Development. Pergamon, 92, pp. 192-202. Doi: 10.1016/J.WORLDDEV. 2016.12.004.

Focus Group Discussion 2020. ODI Available at: https://www. odi.org/publications/5695-researchtools-focus-group-discussion (Accessed 01 September 2020).

Google Earth 2018. Digital Satellite Imagery of Atulia union, Satkhira. Google Earth. Retrieved from: https://earth.google.com/web/@22.322474,89.15974176,1.01564195a,6926.17277109d, $35 \mathrm{y}, 0 \mathrm{~h}, 0 \mathrm{t}, 0 \mathrm{r}$ (Accessed 04 January 2021)

Government of Bangladesh 2008. Cyclone Sidr in Bangladesh: Damage, loss, and needs assessment for disaster recovery and reconstruction - Bangladesh | ReliefWeb. Available at: https://reliefweb.int/report/bangladesh/cyclone-sidr-bangladesh-damage-loss-and-needsassessment-disaster-recovery-and (Accessed: 2 May 2018). 
Government of Bangladesh 2009. Bangladesh Climate Change Strategy and Action Plan. Available at: https://www.iucn.org/content/bangladesh-climate-change-strategy-and-action-plan-2009 (Accessed: 2 May 2018).

Hossain, M.Z., M.T. Islam, T. Sakai and M. Ishida 2008. Impact of Tropical Cyclones on Rural Infrastructures in Bangladesh. Invited Overview. Retrieved from http://www. cigrjournal.org/index.php/Ejounral/article/viewFile/1036/1029

Huq, M., M.F. Khan, K. Pandey, M.M.Z. Ahmed, Z.H. Khan, S. Dasgupta and N. Mukherjee 2010. Vulnerability Of Bangladesh To Cyclones In A Changing Climate: Potential Damages And Adaptation Cost. The World Bank. https://doi.org/10.1596/1813-9450-5280

International Federation of Red Cross and Red Crescent Societies 2002. World Disasters Report 2002. Damage Assessment Report, Dhaka, Bangladesh: International Federation of Red Cross and Red Crescent Societies.

International Federation of Red Cross and Red Crescent Societies 2009. Cyclone Aila Report. Damage Assessment Report, Dhaka, Bangladesh: International Federation of Red Cross and Red Crescent Societies.

IPCC 2014. Fifth Assessment Report (AR5): Synthesis Report. Intergovernmental Panel on Climate Change, Geneva, 2014. Available at: http://www.ipcc.ch/ (Accessed: 28 September 2017).

Islam, D., S.M. Bhuiyan and A.L. Ramanathan 2015. Climate change impacts and vulnerability assessment in coastal region of Bangladesh: a case study on Shyamnagar upazila of Satkhira District. Journal of Climate Change 1,2:37-45.

Jia, Z. 2010. Cyclone Shelters and Cyclone Resilient Design in Coastal Areas of Bangladesh. Thesis, Department of Urban Studies and Planning, Tsinghua University.

Khan, S.R. 1995. Cyclone Hazard in Bangladesh, Case Study in Coastal Hazard Assessment. ADPC. Available at: http://www.adpc.net/casita/Case_studies/Coastal hazard assessment/ modelling cyclone hazard in Bangladesh/ Background_information_on_ the storm surge_modelling.pdf (Accessed: 1 May 2018).

Local Government Engineering Department 2018. Administrative Boundaries. Available at: http://gis.lged.gov.bd/Map/Public/published-map (Accessed 23 September 2020)

Paul, B.K. 2009. Why relatively fewer people died? The case of Bangladesh's Cyclone Sidr. Natural Hazards, 50(2), 289-304. https://doi.org/10.1007/s11069-008-9340-5

Paul, S.K., and Routray, J.K. 2013. An Analysis of the Causes of Non-Responses to Cyclone Warnings. In Climate Change Management, Springer. https://doi.org/10.1007/978-3-64231110-9_2

Roy, C., S. Sarkar, J. Åberg and R. Kovordanyi 2015. The current cyclone early warning system in Bangladesh: Providers' and receivers' views. International Journal of Disaster Risk Reduction, 12, 285-299. https://doi.org/10.1016/J.IJDRR.2015.02.004

United Nations International Strategy for Disaster Reduction 2011. Global assessment report on disaster risk reduction (2011). Retrieved from: https://www.unisdr.org/ we/inform/ publications/19846 (Accessed 01 September 2020).

World Bank 2010. Poverty maps. http://documents.worldbank.org/curated/en/ 916761468211 763695/pdf/904870WP0WB0Po00Box385319B00PUBLIC0.pdf (Accessed 01 September 2020).

(Revised copy received 27.o9.2020) 